\title{
Cyanuric Chloride-Catalyzed Michael Addition of Indoles to Nitroolefins under Solvent-Free Conditions
}

\author{
Xiao Juan Yang ${ }^{1}$ and Yun Jing ${ }^{2}$ \\ ${ }^{1}$ College of Chemistry and Chemical Engineering, Xinxiang University, Henan, Xinxiang 453003, China \\ ${ }^{2}$ School of Pharmacy, Xinxiang Medical University, Henan, Xinxiang 453003, China \\ Correspondence should be addressed to Xiao Juan Yang; yangxiaojuan2005@126.com
}

Received 28 June 2012; Accepted 27 July 2012

Academic Editor: Grégory Durand

Copyright (C) 2013 X. J. Yang and Y. Jing. This is an open access article distributed under the Creative Commons Attribution License, which permits unrestricted use, distribution, and reproduction in any medium, provided the original work is properly cited.

Cyanuric chloride is an inexpensive, efficient, and mild catalyst for the Michael addition of indoles to nitroolefins at $70^{\circ} \mathrm{C}$ under solvent-free conditions. The simple experimental procedure, solvent-free reaction conditions, utilization of an inexpensive and readily available catalyst, short period of conversion, and excellent yields are the advantages of the present method.

\section{Introduction}

The indole nucleus is an important structural motif in medicinal chemistry [1-3]. Substituted indoles have been referred to as privileged structures as they are capable of binding to many receptors with high affinity [4-6]. Therefore, the synthesis and selective functionalization of indoles have been the focus of active research over the years $[7,8]$. Since the 3 position of the indole is the ideal site for electrophilic attack, 3 -substituted indoles are versatile intermediates for the synthesis of a wide variety of indole derivatives. Commonly indole 3-derivatives are prepared by the Michael addition of indoles with $\beta$-nitrostyrenes in the presence of dodecyl sulfate scandium(III)salt [9], $\mathrm{InCl}_{3}[10], \mathrm{InBr}_{3}$ [11], $\mathrm{Bi}(\mathrm{OTf})_{3}$ [12], [Al(DS) $\left.{ }_{3}\right] \cdot 3 \mathrm{H}_{2} \mathrm{O}$ [13], $\mathrm{SmI}_{3}[14], \mathrm{I}_{2}$ [15], $\mathrm{KHSO}_{4}$ [16], sulfamic acid [17], $\mathrm{Bi}\left(\mathrm{NO}_{3}\right)_{3} \cdot 5 \mathrm{H}_{2} \mathrm{O}$ [18], $\beta$-cyclodextrin [19], $\mathrm{Zn}(\mathrm{OAc})_{2}$ [20], $\mathrm{TiO}_{2}$ [21], Montmorillonite $\mathrm{K} 10$ [22], $\mathrm{CoCl}_{2}$ [23]. In view of the importance of the indole 3-derivatives, there still remains the necessity to develop a new methodology.

Cyanuric chloride (2,4,6-Trichlorotriazine, TCT) is a stable, nonvolatile, inexpensive, and safe reagent which has been used synthetically for the preparation of various types of compounds such as 2-aryl-2,3-dihydroquinolin-4(1H)ones [24], bis(indolyl)methanes [25], N-sulfonyl imines [26], and 14-aryl or alkyl-14- $H$-dibenzo[ $a, j]$ xanthenes [27]. In this paper, we wish to report a rapid and highly efficient method for the Michael addition of indoles to nitroolefins in the presence of TCT at $70^{\circ} \mathrm{C}$ under solvent-free conditions (Scheme 1).

\section{Experimental}

General Procedure for the Preparation of 3. A mixture of indoles ( $1 \mathrm{mmol})$, nitroolefins $(1 \mathrm{mmol})$, and TCT $\left(0.1 \mathrm{mmol}\right.$ ) was heated at $70^{\circ} \mathrm{C}$ for the appropriate time (Table 2) under wet air atmosphere. The reaction was monitored by TLC. After completion of the reaction, the mixture was cooled to room temperature and washed with water. The solid products were purified by column chromatography using acetone-petroleum ether $(v: v=1: 8)$ as eluent. All the compounds are known and their physical properties are the same as the reported values. ${ }^{1} \mathrm{H}$ NMR and ${ }^{13} \mathrm{C}$ NMR, and elemental analysis data of all the products match the reported data.

\section{Results and Discussion}

Initially, we chose indole (1a) and the commercially available $\beta$-nitrostyrene (2a) as starting materials to establish the best conditions for the reaction. The optimum catalyst loading for TCT was found to be $10 \mathrm{~mol} \%$. When the amount of the catalyst was decreased to $51 \mathrm{~mol} \%$, the yield of the product 
<smiles>[R]1ccc2[nH]ccc2c1</smiles>

1<smiles>O=[N+]([O-])C=CBr</smiles>

2

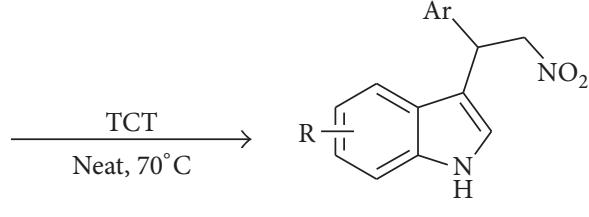

3

SCHEMe 1

TABLE 1: Synthesis of 3-(2-nitro-1-phenylethyl)- $1 H$-indole under various conditions ${ }^{\mathrm{a}}$.

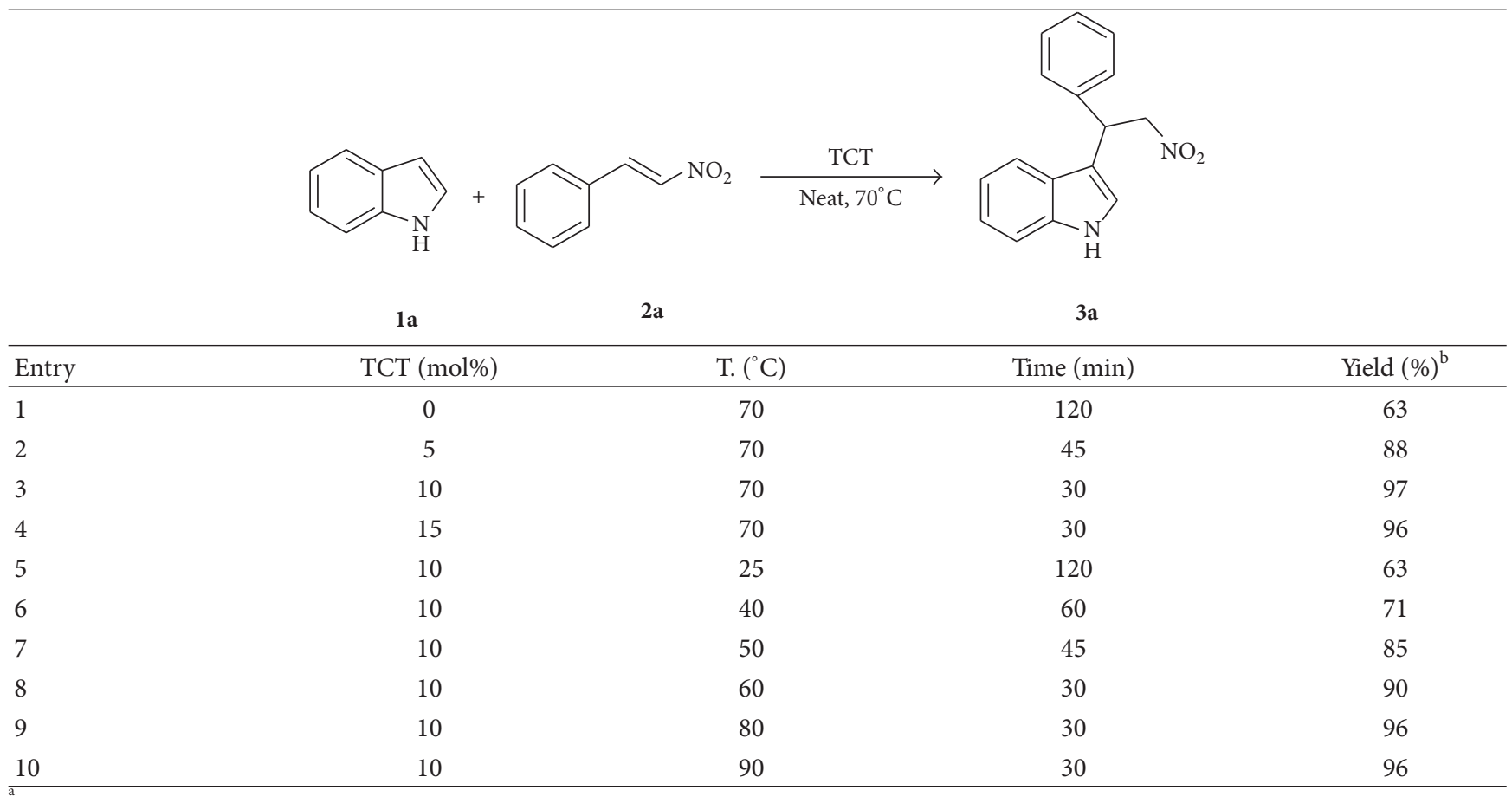

Reaction conditions: indole ( $1 \mathrm{mmol}) ; \beta$-nitrostyrene ( $1 \mathrm{mmol})$; neat.

${ }^{\mathrm{b}}$ Isolated yield.

3a was reduced considerably but with $15 \mathrm{~mol} \%$ loading of the catalyst, no further improvement of the yield was observed (Table 1). To screen for the practical temperatures for the solvent-free synthesis, the previous reaction was run in on a $1 \mathrm{mmol}$ scale of substrate at different temperature (Table 1). As shown in Table 1, the reaction at $70^{\circ} \mathrm{C}$ proceeded in highest yield among the seven reaction temperatures tested. So $70^{\circ} \mathrm{C}$ was chosen for this reaction.

Based on the optimized reaction conditions, a series of 3(2-nitro-1-arylethyl)-1 $H$-indole derivatives was synthesized. As shown in Table 2, the reaction under solvent-free and $10 \mathrm{~mol} \%$ TCT conditions gave the corresponding product in good yields. The electronic effects and nature of substituents on the nitroolefins did not show a strongly obvious difference in terms of yields. This protocol can be applied not only to nitroolefins either with electron-withdrawing groups (such as a nitro group, halogen) or electron-donating groups (such as a methoxy group) but also to hetero-aromatic nitroolefins with excellent yields under the same conditions. Substituents on the indole ring do not have an effect on the adduct formation.

$\mathrm{HCl}$ generated in situ, from cyanuric chloride, efficiently catalyzes these reactions. Accordingly, cyanuric chloride (10 mol \%) reacts with "incipient" moisture and releases three moles of $\mathrm{HCl}$ and cyanuric acid (removable by washing with water) as a by-product. The in situ-generated $\mathrm{HCl}$ acts as protic acid and activates the Michael addition. The reaction could be facilitated by wet glass wares or by the presence of wet air. However, the reaction under dry reaction conditions in the presence of MS $4 \AA$ met with failure. Thus, it amply indicates that the "incipient" moisture plays an important role for $\mathrm{HCl}$ generation in situ from TCT.

\section{Conclusion}

In summary, a new catalytic protocol for the Michael addition of indoles to nitroolefins has been developed. Compared with previous reported methodologies, the present protocol features simple work-up, easy, and quick isolation of the 
TABLE 2: Michael addition of indoles to nitroolefins catalyzed by TCT under solvent-free condition.

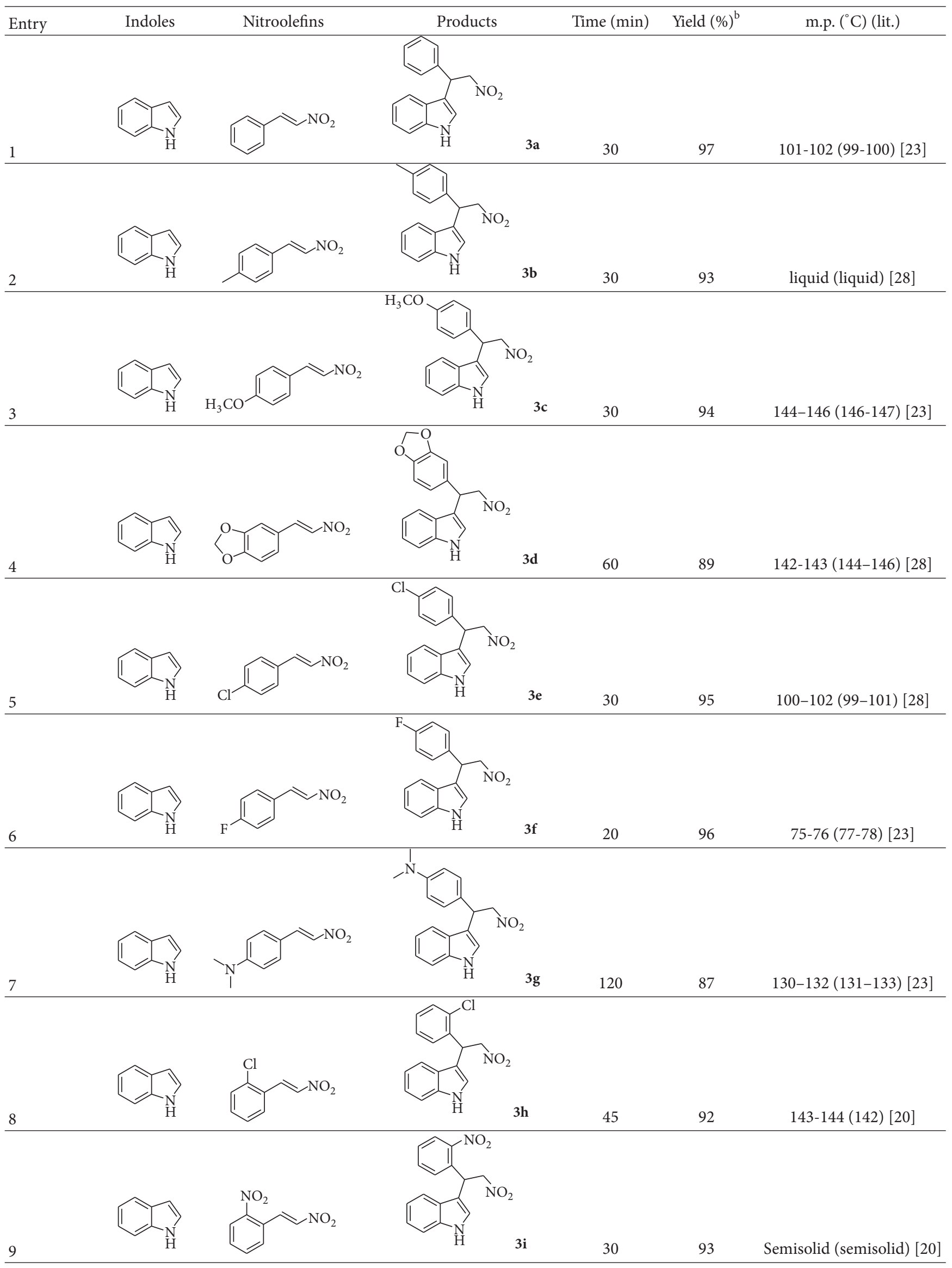


TABLe 2: Continued.

\begin{tabular}{|c|c|c|c|c|c|c|}
\hline Entry & Indoles & Nitroolefins & Products & Time (min) & Yield $(\%)^{b}$ & m.p. $\left({ }^{\circ} \mathrm{C}\right)$ (lit.) \\
\hline 10 & & & & 20 & 98 & $144-145(145-147)[28]$ \\
\hline 11 & & & & 30 & 92 & $70-71(67-68)[17]$ \\
\hline 12 & & & & 30 & 90 & $85-86(86-87)[23]$ \\
\hline 13 & & & & 60 & 95 & 98-99 (95-97) [17] \\
\hline 14 & & & & 60 & 89 & $100-101(102-103)[23]$ \\
\hline 15 & & & . & 45 & 94 & $129-131(130-131)$ [23] \\
\hline 16 & & & & 60 & 88 & $113-115(112-114)[17]$ \\
\hline 17 & & & & 45 & 90 & $106-107(107-108)[17]$ \\
\hline 18 & & & & 90 & 89 & $141-143(143-145)[28]$ \\
\hline
\end{tabular}

Reaction conditions: indoles $(1 \mathrm{mmol})$; nitroolefins $(1 \mathrm{mmol})$; TCT $(0.1 \mathrm{mmol}) ;$ neat; $70^{\circ} \mathrm{C}$. ${ }^{\mathrm{b}}$ Isolated yield. 
products, cheap and a catalytic amount of catalyst. This protocol avoids the use of hazardous solvent and toxic metallic catalysts and is of low cost.

\section{Acknowledgment}

The authors are pleased to acknowledge the financial support from Xinxiang University.

\section{References}

[1] R. J. Sundberg, Indoles, Academic Press, New York, NY, USA, 1996.

[2] D. J. Faulkner, "Marine natural products," Natural Product Reports, vol. 18, no. 1, pp. 1-49, 2001.

[3] I. Ninomiya, "Recent progress in the synthesis of indole alkaloids," Journal of Natural Products, vol. 55, no. 5, pp. 541-564, 1992.

[4] T. L. Gilchrist, "Synthesis of aromatic heterocycles," Journal of the Chemical Society. Perkin Transactions 1, no. 20, pp. 2491-2515, 2001.

[5] D. A. Horton, G. T. Bourne, and M. L. Smythe, "The combinatorial synthesis of bicyclic privileged structures or privileged substructures," Chemical Reviews, vol. 103, no. 3, pp. 893-930, 2003.

[6] J. Tois, R. Franzén, and A. Koskinen, "Synthetic approaches towards indoles on solid phase recent advances and future directions," Tetrahedron, vol. 59, no. 29, pp. 5395-5405, 2003.

[7] S. Cacchi and G. Fabrizi, "Synthesis and functionalization of indoles through palladium-catalyzed reactions," Chemical Reviews, vol. 105, no. 7, pp. 2873-2920, 2005.

[8] G. R. Humphrey and J. T. Kuethe, "Practical methodologies for the synthesis of indoles," Chemical Reviews, vol. 106, no. 7, pp. 2875-2911, 2006.

[9] K. Manabe, N. Aoyama, and S. Kobayashi, "Friedel-Crafts-type conjugate addition of indoles using a Lewis acid-surfactantcombined catalyst in water," Advanced Synthesis and Catalysis, vol. 343, no. 2, pp. 174-176, 2001.

[10] J. S. Yadav, S. Abraham, B. V. S. Reddy, and G. Sabitha, " $\mathrm{InCl}_{3}$ catalysed conjugate addition of indoles with electron-deficient olefins," Synthesis, no. 14, pp. 2165-2169, 2001.

[11] M. Bandini, P. Melchiorre, A. Melloni, and A. Umani-Ronchi, "A practical indium tribromide catalysed addition of indoles to nitroalkenes in aqueous media," Synthesis, no. 8, pp. 1110-1114, 2002.

[12] M. M. Alam, R. Varala, and S. R. Adapa, "Conjugate addition of indoles and thiols with electron-deficient olefins catalyzed by Bi(OTf) ${ }_{3}$, Tetrahedron Letters, vol. 44, no. 27, pp. 5115-5119, 2003.

[13] H. Firouzabadi, N. Iranpoor, and F. Nowrouzi, "The facile and efficient Michael addition of indoles and pyrrole to $\alpha, \beta$ unsaturated electron-deficient compounds catalyzed by aluminium dodecyl sulfate trihydrate $\left[\mathrm{Al}(\mathrm{DS})_{3}\right] \cdot 3 \mathrm{H}_{2} \mathrm{O}$ in water," Chemical Communications, no. 6, pp. 789-791, 2005.

[14] Z. P. Zhan, R. F. Yang, and K. Lang, "Samarium triiodidecatalyzed conjugate addition of indoles with electron-deficient olefins," Tetrahedron Letters, vol. 46, no. 22, pp. 3859-3862, 2005.

[15] C. Lin, J. Hsu, M. N. V. Sastry et al., " $\mathrm{I}_{2}$-catalyzed Michael addition of indole and pyrrole to nitroolefins," Tetrahedron, vol. 61, no. 49, pp. 11751-11757, 2005.
[16] R. S. Kumar and P. T. Perumal, "Michael addition of indoles to electron deficient olefins in water catalysed by potassium bisulfate," Journal of Heterocyclic Chemistry, vol. 43, no. 5, pp. 1383-1385, 2006.

[17] L. T. An, J. P. Zou, L. L. Zhang, and Y. Zhang, "Sulfamic acid-catalyzed Michael addition of indoles and pyrrole to electron-deficient nitroolefins under solvent-free condition," Tetrahedron Letters, vol. 48, no. 24, pp. 4297-4300, 2007.

[18] M. M. Khodaei, P. Ghanbary, I. Mohammadpoor-Baltork, H. R. Memarian, A. R. Khosropour, and K. Nikoofar, "Synthesis of 3-substituted indoles promoted by pulverization-activation method catalyzed by $\mathrm{Bi}\left(\mathrm{NO}_{3}\right) 3 \cdot 5 \mathrm{H}_{2} \mathrm{O}$," Journal of Heterocyclic Chemistry, vol. 45, no. 2, pp. 377-381, 2008.

[19] V. P. Kumar, R. Sridhar, B. Srinivas, M. Narender, and K. R. Rao, "Friedel-Crafts alkylation of indoles with nitroolefins in the presence of $\beta$-cyclodextrin in water under neutral conditions," Canadian Journal of Chemistry, vol. 86, no. 9, pp. 907-911, 2008.

[20] H. M. Meshram, D. A. Kumar, and B. C. Reddy, "Simple and efficient Friedel-Crafts alkylation of $1 \mathrm{H}$-indole with electrondeficient alkenes promoted by zinc acetate," Helvetica Chimica Acta, vol. 92, no. 5, pp. 1002-1006, 2009.

[21] M. L. Kantam, S. Laha, J. Yadav, and P. Srinivas, "Synthesis of 2-indolyl-1-nitroalkane derivatives using nanocrystalline titanium(IV) oxide," Synthetic Communications, vol. 39, no. 22, pp. 4100-4108, 2009.

[22] L. T. An, L. L. Zhang, J. P. Zou, and G. L. Zhang, "Montmorillonite K10: catalyst for Friedel-Crafts alkylation of indoles and pyrrole with nitroalkenes under solventless conditions," Synthetic Communications, vol. 40, no. 13, pp. 1978-1984, 2010.

[23] C. S. Schwalm, M. A. Ceschi, and D. Russowsky, "Metal halide hydrates as lewis acid catalysts for the conjugated FriedelCrafts reactions of indoles and activated olefins," Journal of the Brazilian Chemical Society, vol. 22, no. 4, pp. 623-636, 2011.

[24] C. Yang, L. Fang, L. Wu, and F. Yan, "Synthesis of 2-aryl2,3-dihydroquinolin-4(1H)-ones using wet cyanuric chloride under solvent-free conditions," Asian Journal of Chemistry, vol. 22, no. 8, pp. 6031-6034, 2010.

[25] G. V. M. Sharma, J. J. Reddy, P. S. Lakshmi, and P. R. Krishna, "A versatile and practical synthesis of bis(indolyl)methanes/ bis(indolyl) glycoconjugates catalyzed by trichloro-1,3,5triazine," Tetrahedron Letters, vol. 45, no. 41, pp. 7729-7732, 2004.

[26] L. Q. Wu, X. J. Yang, X. Wang, and F. L. Yan, "Cyanuric chloride-catalyzed synthesis of N-sulfonyl imines," Journal of Sulfur Chemistry, vol. 31, no. 6, pp. 509-513, 2010.

[27] M. A. Bigdeli, M. M. Heravi, and G. H. Mahdavinia, "Wet cyanuric chloride catalyzed simple and efficient synthesis of 14aryl or alkyl-14-H-dibenzo[ $a, j]$ xanthenes," Catalysis Communications, vol. 8, no. 11, pp. 1595-1598, 2007.

[28] P. M. Habib, V. Kavala, C. W. Kuo, M. J. Raihan, and C. F. Yao, "Catalyst free conjugate addition of indoles and pyrroles to nitro alkenes under solvent free condition (SFC): an effective greener route to access 3-(2-nitro-1-phenylethyl)- $1 H$-indole and 2-(2nitro-1-phenylethyl)- $1 H$-pyrrole derivatives," Tetrahedron, vol. 66, no. 34, pp. 7050-7056, 2010. 

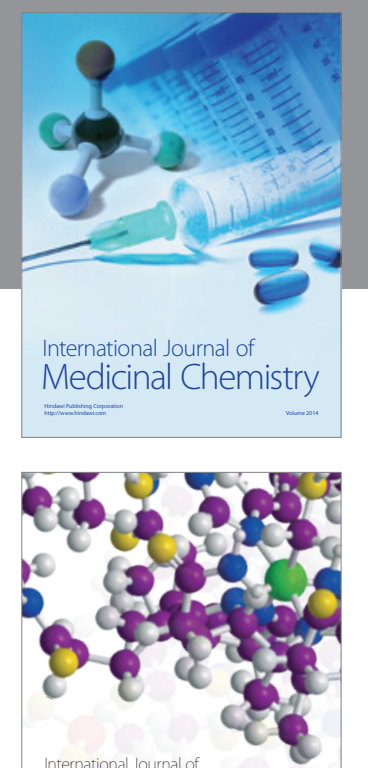

\section{Carbohydrate} Chemistry

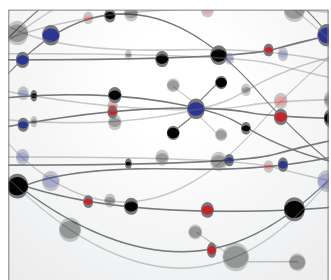

The Scientific World Journal
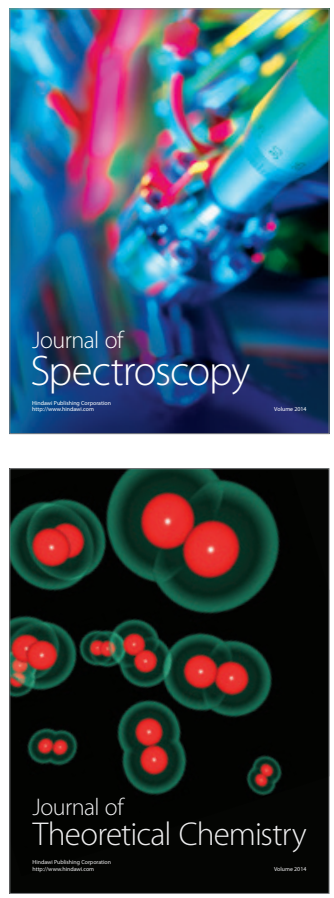
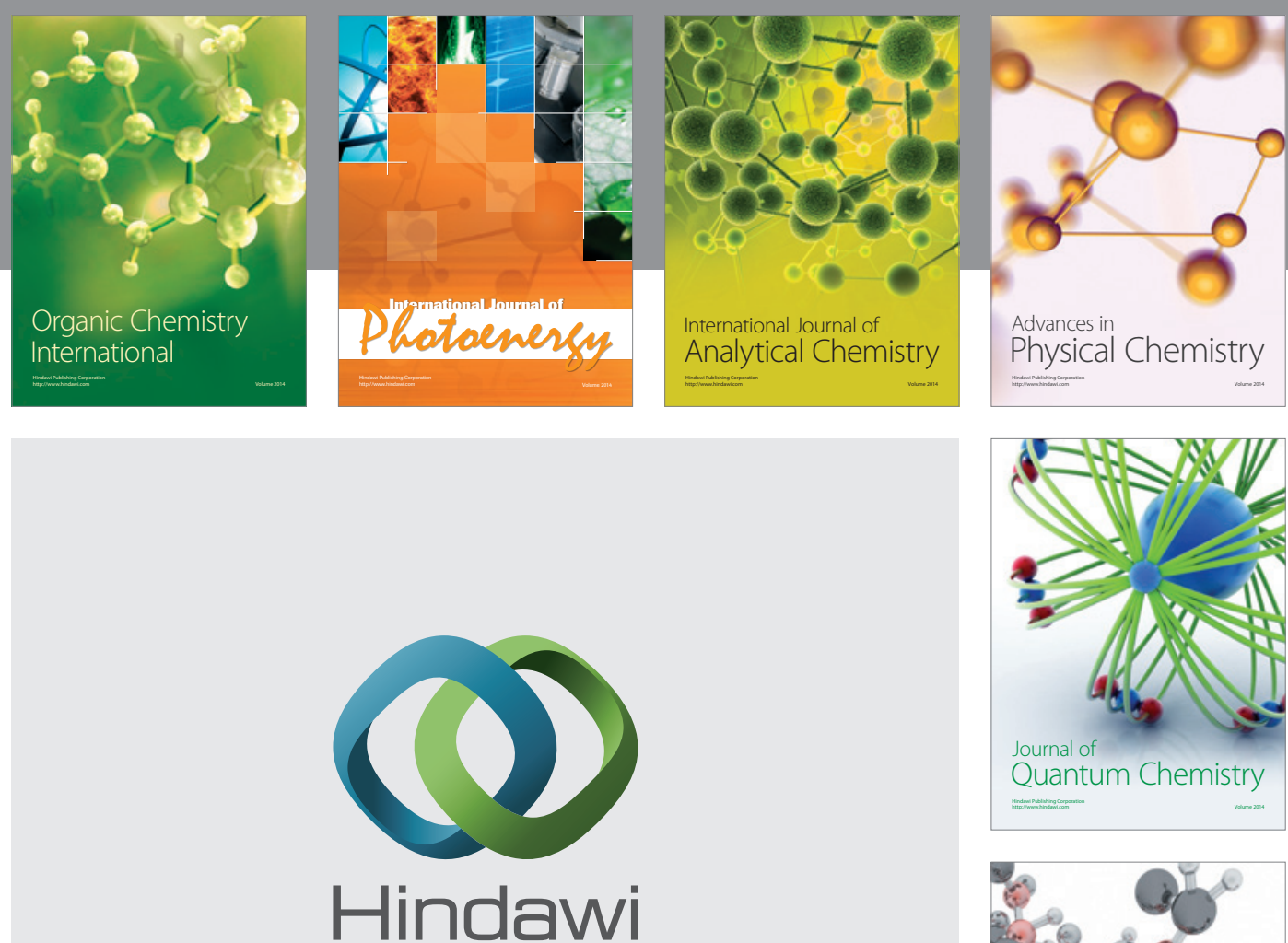

Submit your manuscripts at

http://www.hindawi.com

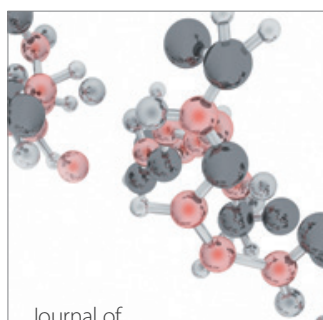

Analytical Methods

in Chemistry

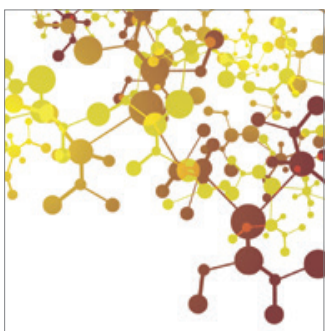

Journal of

Applied Chemistry

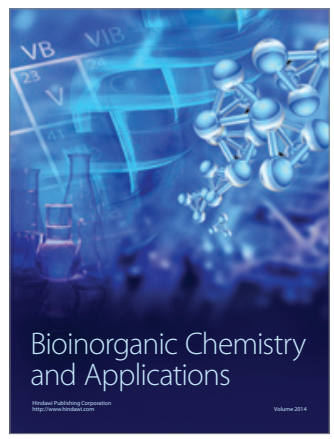

Inorganic Chemistry
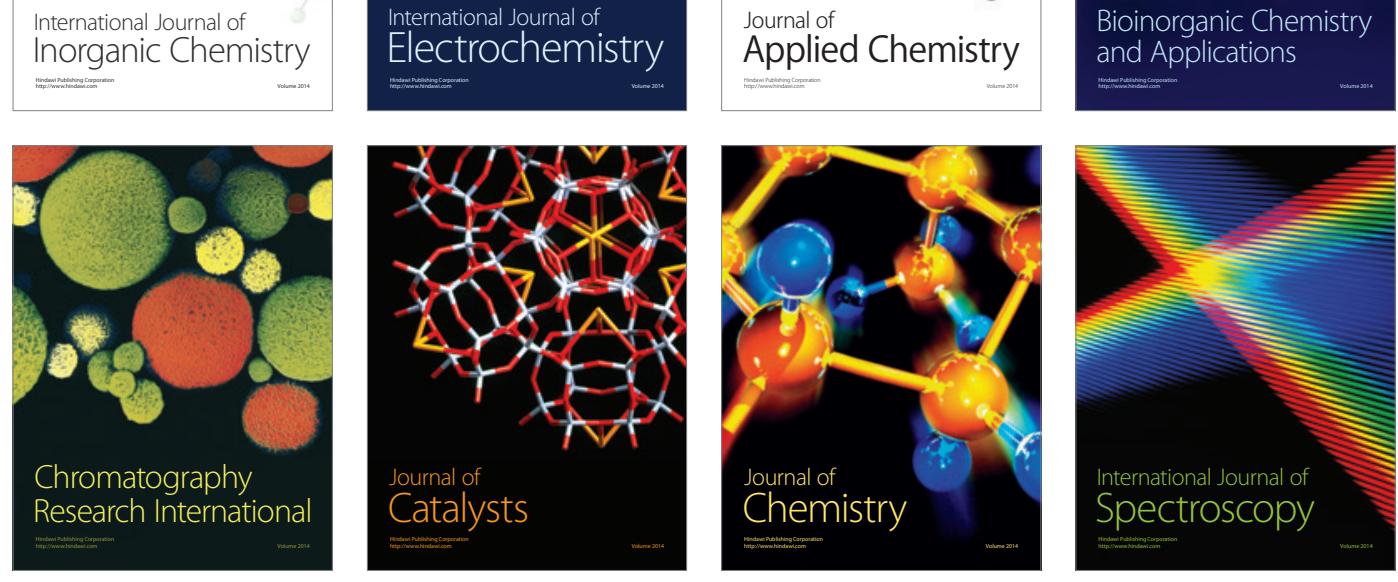